\title{
DETERMINING YIELD STABILITY AND MODEL SELECTION BY AMMI METHOD IN RAIN-FED DURUM WHEAT GENOTYPES
}

\author{
Rahmatollah KARIMIZADEH ${ }^{1,3}$, Ali ASGHARI ${ }^{1}$, Rahim CHINIPARDAZ ${ }^{2}$, \\ Omid SOFALIAN ${ }^{I}$, Abdolali GHAFFARI ${ }^{4}$ \\ ${ }^{1}$ University of Mohaghegh Ardabili, Faculty of Agricultural Science, Department of Agronomy and Plant \\ Breeding, Ardabil, IRAN \\ ${ }^{2}$ Shahid Chamran University of Ahvaz, Ahvaz, IRAN \\ ${ }^{3}$ Dryland Agricultural Research Institute, Agricultural Research, Education and Extension Organization \\ (AREEO), Gachsaran, IRAN \\ ${ }^{4}$ West Azarbaijan Agricultural and Natural Resources Research and Education Center, Agricultural \\ Research, Education and Extension Organization (AREEO), IRAN \\ *Corresponding author: karimizadeh_ra@yahoo.com
}

Received: 16.06.2016

\begin{abstract}
Selection of durum wheat genotypes with wide adaptability across various environments is important before recommending them to reach a high rate of genotype adoption. Multi-environment grain yield trials of 20 durum wheat genotypes were conducted at five locations of Iran (Gachsaran, Gonbad, Moghan, Ilam and Khorram abad) over four years (2009-2013). Combined ANOVA of yield data of the 20 environments revealed highly significant differences among genotypes and environments as well as significant GE interaction indicated differential performance of genotypes over test environments. Results of $F$ Ratio indicated that only five interaction principal components (IPCs) were significant at the 0.01 probability level. Also, the GE interaction is comprised of $29.7 \%$ noise and $\mathbf{7 0 . 0 3 \%}$ signal. According to these distinct numbers of significant axes, fourteen AMMI stability parameters were computed. Finally according to the most of type 1 of AMMI parameters (EV1, AMGE1, SIPC1 and D1), genotypes G8, G17 and G11; based on the type 2 of AMMI parameters and ASV, genotypes G4, G5, G10, G11 and G17; due to type 3 of AMMI parameters and MASV, genotypes G8, G10 and G12 were detected as the most stable genotypes. Considering all of the AMMI stability parameters, genotypes G8, G10, G11, G12 and G17 following to genotypes G7 and G9 were the most stable genotypes. The best recommended genotypes according to the present study are $\mathbf{G 1 0}$ with $3470 \mathrm{~kg} \mathrm{ha}^{-1} \mathrm{grain}^{-}$ yield for Gachsaran and Khorramabad, G12 with $3343 \mathrm{~kg} \mathrm{ha}^{-1}$ grain yield for Ilam and G10 and G12 for Moghan and Gonbad regions wich had high mean yield and were most stable for related mega-environments.
\end{abstract}

Keywords: AMMI, Durum wheat, GE interaction, Yield stability.

\section{INTRODUCTION}

The exploring for genotypes with high mean yield adapted in the most various environments is one of the most important objectives for durum wheat breeders. The presence of differential genotypic responses in different test environments, known as the genotype $\times$ environment (GE) interaction, is a usual phenomenon in most plant breeding programs (Kang, 1998; Adugna and Labuschagne, 2002; Akcura et al., 2009; Karimizadeh et al., 2012b; Mohammadi et al., 2012). Thus, the choice of genotypes which indicate good genetic homeostasis is essential for yield increases. The GE interaction governs the identification of the most stable genotypes that are suitable for specific environment, as well as of genotypes with a general response that are suitable for several test environments (Annicchiarico, 2002). The measure of GE interaction is important, because it can be used to establish the breeding targets, such as the choice of parents and recommendations for regional adapted cultivars (Yan et al., 2000).

The presence of genotype-environment interaction (GEI) in a multi-environment trial (MET) is expressed either as inconsistent responses of some genotypes with respect to others due to the alteration of the ordering of the genotypes from one environment to another (GEI with rank change or crossover interaction) or as changes in the absolute differences between genotypes without rank change (GEI without rank change or non-crossover interaction). Fisher and MacKenzie (1923), who analyzed data from an experiment evaluating 12 potato cultivars under each of six soil-fertilization treatments, were the first authors to propose breaking down the response into a 
series of multiplicative terms fitted by least squares; however, this work was apparently forgotten for many years. Yates and Cochran (1938) proposed breaking down the GEI into one multiplicative term and a deviation therefore, examining whether the GEI is a linear function of the additive environmental component. This regression approach expresses the GEI simply as heterogeneity of slopes and was later used by Finlay and Wilkinson (1963) and slightly modified by Eberhart and Russell (1966). Tukey (1949) proposed a test for the GE and Mandel (1961) generalized Tukey's (1949) Model. Mandel (1971) computed the number of degrees of freedom associated with the sum of squares (SS) due to each of the first three bilinear terms in Equation 1 by a Monte Carlo study, and Johnson and Graybill (1972) found that Mandel's (1971) results were close to the exact values. Gabriel (1978) showed that a least-squares (LS) solution for model parameters in Equation 1 can be obtained by taking the estimates of the bilinear terms as the $t$ largest components of the singular value decomposition (SVD) of the $\mathrm{Z}$ matrix $\left(Z_{i j}=X_{i j}-X_{i 0}-X_{0 j}+\bar{X}_{00}\right)$ with the additive (linear) effects estimated as we have previously given for their estimates in the two-way fixed effects model.

$$
Y_{i j}=\mu+g_{i}+e_{j}+\sum_{n=1}^{N} \lambda_{n} \gamma_{i n} \delta_{j n}+\rho_{i j}
$$

Zobel et al. (1988) and Gauch (1988) named Equation 1 the 'additive main effects and multiplicative interaction (AMMI) model. They further introduced a data-splitting and cross-validation procedure for determining the number of multiplicative components to retain in a truncated AMMI model. The AMMI model and four other linear bilinear models and their least square estimates were described and unified in one general methodology by Cornelius et al. (1996). These authors described various statistical tests for the significance of the bilinear terms and mentioned the possibility of using shrinkage estimates of these models for improving the prediction of the GE cells.

The widely used statistical method for characterizing GE interaction and to predict genotypic response was proposed by (Finlay and Wilkinson, 1963). This procedure needs analysis of stability parameters (line slope and deviation from linearity) of crop genotype performance over a series of trials. The linear regression model has some problems such as confounding between GE interaction with the main effects of genotypes or environments, and nonlinear response of genotypes to test environments (Nachit, 1992; Annicchiarico, 1997). Also, the variation of the regression coefficients' estimates is usually so small and so the classification of the genotype for stability is difficult (Yue et al., 1997). Williams (1952), Gollob (1968), and Mandel (1971) have made an important contribution to the development of additive main effects and multiplicative interaction (AMMI) models. Gauch (1988) and Zobel et al. (1988) suggested the AMMI model for investigating multi-environment experiments and compared with analysis of variance, linear regression, and principal component analysis. The AMMI model has been used to analyze multi-environment trials because of its good flexibility in permitting the use of several multiplicative terms to explain the GE interaction.

For all models that include singular value decomposition (SVD) matrix, the main question that researcher do not yet have an answer to is which test to apply for testing multiplicative components. Crossvalidation method is the one of the solutions that has been offered to select an optimal multiplicative term (Gauch, 1988). Random partitioning of the data set into K groups is the basic idea for cross-validation procedure. Then, the reduced data set is formed by deleting the first group and estimating the parameters of the model on the basis of the reduced data set. By using these parameters, the model values are calculated for the objects in the deleted group. Then the sum of squares of prediction errors is calculated from the predicted values and observed values of the deleted objects. The procedure is repeated for the new reduced data set several times (Wold, 1978). Then, the Root Mean Square Predictive Difference (RMSPD) between the model and the validation observations (deleted group) is calculated as the square root of the quantity of the sum of square differences between the estimated model and the the validation observations which is divided by the number of validation observation (Ebdon and Gauch, 2002). The advantage of cross-validation application is that the predictive accuracy of gain factor (statistical efficiency) associated with the AMMI model is increased, which is equivalent to increasing the number of replications in the data set (Ebdon and Gauch, 2002; Gauch, 2006). Thus, estimates from two adjusted replicates are more accurate than the unadjusted means of the same replicates. By using the cross-validation procedure, noise is typically filtered from the data pattern. Therefore, the predictive accuracy is more interpretable and it provides a simple guide for model diagnosis by keeping the early axes that are mostly patterned than to discarded residual (Gauch, 1988).

The AMMI model has been detected as an innovative methodology in graphic analysis to be applied in plant breeding programs (Gauch, 2006; Gauch et al., 2008; Ilker et al., 2011; Mladenov et al., 2012). The megaenvironment analysis through AMMI model can be regarded a true tool because it discovers the "which-wonwhere" pattern. Sabaghnia et al. (2008) and Karimizadeh and Mohammadi (2010) reported an AMMI analysis of grain yield of some durum wheat genotypes grown in semi-arid areas and reported that several interaction principal components analysis (IPCAs) were necessary to explain the sum of squares of GE interaction. Solomon et al. (2008) used parametric and AMMI methods for determining GE interaction of some durum wheat genotypes grown in South Africa. The AMMI model can help to identify highly productive and broadly adaptable genotypes, and to establish region specific recommendations (Gauch and Zobel, 1996). The AMMI model has been reported to be more effective than the 
conventional two way model with interactions. According to Gauch and Zobel (1997), the AMMI model achieves both parsimony (contains relatively few degrees of freedom for the interaction), and effectiveness (contains most of the interactions sum of squares) in analysis of multi-environment trials.

Yield stability can be assessed by AMMI analysis as the different statistical stability parameters. Zobel (1994) introduced averages of the squared eigenvector (EV) values as the AMMI stability parameter. Sneller et al. (1997) suggested AMGE and SIPC stability parameters of AMMI model to describe the contribution of environments to GE interaction. The AMMI stability value (ASV) benefits from the first two IPCA of AMMI model (Purchase, 1997) and modified AMMI stability value proposed by Zali et al. (2012). The Euclidean distance from the origin of significant interaction IPCA axes as D parameter was suggested by Annicchiarico (1997). The use of the AMMI stability parameters permits to evaluate yield stability after reduction of the noise from the GE interaction effects. Any of these parameters may also be of interest for breeding programs as an alternative to the conventional stability methods such as joint linear regression model. This investigation was carried out to evaluate the effect of GE interaction on the yield performance of cultivars and improved genotypes of durum wheat in semiarid areas of Iran.

The objectives of this study were to evaluate stability of durum wheat genotypes across test environments, to evaluate the GE interaction for grain yield of durum wheat, and to evaluate the relationship of test environments for selecting superior genotypes within the mega-environment using AMMI model.

\section{MATERIALS AND METHODS}

\section{Field Trials}

The data used in the yield analyses are from 19 genotypes with one local check cultivar (Dehdasht) grown for 4 years (2009-2013) at each of five locations in Iran (genotype names and pedigrees is in Table 1). The trial locations were selected to sample climatic and edaphic conditions likely to be encountered in rain-fed durum wheat growing throughout Iran and to vary in latitude, rainfall, soil types, temperature and other agro-climatic factors. Moghan (Mn) in north of Iran, Gonbad (Gd) in the north-east of Iran, that these areas are characterized by semi-arid conditions and have sandy loam soil. Khorram abad (Kd) and Ilam (Im), in western Iran, Gachsaran (Gn), in southern Iran, is relatively arid and has silt loam soil. The experimental plant seed materials were from national durum wheat improvement program for rain-fed areas and the International Centre for Agricultural Research in the Dry Areas (ICARDA) durum wheat breeding program. The experimental design, at each location, in each year, was a randomized complete block with four replicates. Plots were planted at a seeding rate of 300 seed per $\mathrm{m}^{2}$ by WINTERSTEIGER AG trial drilling machine. Plot size was containing six rows $(7.03 \mathrm{~m}$ long) with row differences of 17.5 centimeters. Fertilizers were applied $80 \mathrm{~kg} \mathrm{ha}^{-1}$ of nitrogen and $80 \mathrm{~kg} \mathrm{ha}^{-1}$ of phosphorus as 40.40.0 composes at planting time, $80 \mathrm{~kg} \mathrm{ha}^{-1}$ of nitrogen as ammonium nitrate (half of the top dressed fertilizer) was given at tillering, and the other half of the top dressed fertilizer was given at swollen stage. No disease was shown during growth period, and weed control was made by chemical method (Topic and Granstar poisons). After physiological maturity, plots were harvested by WINTERSTEIGER AG trial thrasher machine. Regional climatic data during growth seasons used to in Table 2 .

\section{Statistical analysis}

Mean grain yield data of the experiment were statistically treated by AMMI model analysis. This analysis consists in the sequential fitting of a model of analysis of experiments, initially by ANOVA (additive fitting of the main effects) and then by analysis of principal components (multiplicative fitting of the effects of interaction). The model AMMI equation is:

$$
Y_{i j}=\mu+g_{i}+e_{j}+\sum_{n=1}^{N} \lambda_{n} \gamma_{i n} \delta_{j n}+\rho_{i j}
$$

where $Y_{i j}$ is the yield of the $i$ th genotype in the $j$ th environment; $\mu$ is the grand mean; $g_{i}$ and $e_{j}$ are the genotype and environment deviations from the grand mean, respectively; $\lambda_{n}$ is the eigenvalue of the IPC analysis axis $\mathrm{n} ; \gamma_{i n}$ and $\delta_{j n}$ are the genotype and environment eigenvectors for axis $n$; $n$ is the number of principal components retained in the model and $\rho_{i j}$ is the error term. The analysis was implemented by SAS software with the routine available by Burguenoet al. (2000).

According to different results of significant numbers of IPCAs through $F_{\text {test }}$ and cross validation, various AMMI parameters were computed. Three types of EV (Zobel, 1994), AMGE and SIPC (Sneller et al., 1997) and D parameters (Annicchiarico, 1997) were calculated. Also, the AMMI's stability value (ASV) and the Modified AMMI's stability value (MASV) were calculated (Purchase, 1997) using two first numbers of IPCAs and significant numbers of IPCAs, respectively. The formulae for computing these AMMI stability parameters are summarized in Table 3. All parameters were computed using the statistical package Genstat release 12.0 (Payne et al., 2009). 
Table 1. Pedigree and origin of the 20 durum wheat genotypes studied in multi-environmental trials

\begin{tabular}{|c|c|c|}
\hline Code & Name/Pedigree & Origin \\
\hline G1 & $\begin{array}{l}\text { ACUATICO_1/RASCON_33//ACUATICO_1/3/AJAIA_12/F3LOCAL(SEL.ETHIO.135. } \\
\text { 85)//PLATA_13CDSS96Y00570S-8Y-0M-0Y-1B-0Y-0B-0B }\end{array}$ & CIMMYT \\
\hline G2 & GAUNT_10/SNITANCDSS97Y00638S-4Y-0M-0Y-0B-0B-3Y-0BLR-1Y-0B & CIMMYT \\
\hline G3 & $\begin{array}{l}\text { SOMO/CROC_4//LOTUS_1/3/KITTI/4/STOT//ALTAR 84/ALDCDSS99Y00636S-0M-0Y-34Y-0M-0Y- } \\
\text { 0B }\end{array}$ & CIMMYT \\
\hline G4 & $\begin{array}{l}\text { CMH82A.1062/3/GGOVZ394//SBA81/PLC/4/AAZ_1/CREX/5/HUI//CIT71/CII/6/STOT//ALTAR } \\
\text { 84/ALDCDSS99Y00643S-0M-0Y-16Y-0M-0Y-0B }\end{array}$ & CIMMYT \\
\hline G5 & $\begin{array}{l}\text { SRN_1/6/FGO/DOM//NACH/5/ALTAR 84/4/ GARZA/AFN//CRA/3/GGOVZ394/7/GEDIZ/ } \\
\text { FGO//GTA/3/CNDO/8/GREEN_38/9/2*STOT//ALTAR 84/ALDCDSS00B00227T-0TOPY-0B-6Y-0M- } \\
\text { 0Y-1B }\end{array}$ & CIMMYT \\
\hline G6 & $\begin{array}{l}\text { LLARETA INIA/YEBAS_8/3/MINIMUS_6/PLATA_16//IMMERCDSS00Y01047T-0TOPB-5Y-0BLR- } \\
\text { 1Y-0B-0Y-1B-0Y }\end{array}$ & CIMMYT \\
\hline G7 & RASCON_21/3/MQUE/ALO//FOJACDSS94Y00099S-7M-0Y-0B-1Y-0B-0BLR-5Y-0B & CIMMYT \\
\hline G8 & $\begin{array}{l}\text { GEDIZ/FGO//GTA/3/SRN_1/4/TOTUS/5/ENTE/MEXI_2//HUI/3/YAV_1/GEDIZ/6/SOMBRA_20/7/ST } \\
\text { OT//ALTAR 84/ALDCD SS97Y00835 S-0TOPM-4Y-0M-0Y-0B-0B-3Y-0BLR-1Y-0B }\end{array}$ & CIMMYT \\
\hline G9 & $\begin{array}{l}\text { STOT//ALTAR 84/ALD/3/THB/CEP7780// 2*MUSK_4CDSS99Y00366 S-3Y-0M-0Y-0BLR-1Y-0B- } \\
\text { 1M-0Y }\end{array}$ & CIMMYT \\
\hline G10 & $\begin{array}{l}\text { ALTAR 84/STINT//SILVER_45/3/STOT// ALTAR 84/ALDCDSS99Y 00373S-7Y-0M-0Y-0BLR-6Y- } \\
\text { 0B-1B-0Y }\end{array}$ & CIMMYT \\
\hline G11 & $\begin{array}{l}\text { STOT//ALTAR 84/ALD/3/GREEN_18/FOCHA_1 //AIRON_1CDSS 99B00467S-0M-0Y-75Y-0M-0Y- } \\
\text { 2M-0Y }\end{array}$ & CIMMYT \\
\hline G12 & $\begin{array}{l}\text { RASCON_21/3/MQUE/ALO//FOJA/4/GREEN_38/BUSHEN_4/5/CADO/BOOMER_33CDSS99B01055 } \\
\text { T-0TOPY-0M-0Y-10Y-0M-0Y-1M-0Y }\end{array}$ & CIMMYT \\
\hline G13 & $\begin{array}{l}\text { STOT//ALTAR 84/ALD*2/3/AUK/GUIL// GREENCDSS00Y00786T-0TOPB-9Y-0BLR-5Y-0B-0Y-1M- } \\
\text { OY } \\
\text { SRN_1/6/FGO/DOM//NACH/5/ALTAR 84/4/ GARZA/AFN//CRA/3/GGOVZ394/7/GEDIZ/ }\end{array}$ & CIMMYT \\
\hline G14 & $\begin{array}{l}\text { FGO//GTA/3/CNDO/8/GREEN_38/9/2*STOT//ALTAR 84/ALDCDSS00B00227T-0TOPY-0B-28Y-0M- } \\
\text { 0Y-1M-0Y }\end{array}$ & CIMMYT \\
\hline G15 & AINZEN-1/SORD_3CDSS99B00317S-0M-0Y-104Y-0M-0Y-1M-0Y & CIMMYT \\
\hline G16 & $\begin{array}{l}\text { PLATA_8/4/GARZA/AFN//CRA/3/GTA/5/RASCON/6/CADO/BOOMER_33/7/STOT//ALTAR } \\
\text { 84/ALDCDSS99B00843S-0TOPY-0M-0Y-5Y-0M-0Y-1B-0Y }\end{array}$ & CIMMYT \\
\hline G17 & $\begin{array}{l}\text { ALTAR 84/STINT//SILVER_45/3/CBC } 503 \text { CHILE/4/AUK/GUIL// GREENCD SS99B01115T -0TOPY- } \\
\text { 0M-0Y-1Y-0M-0Y-1B-0Y }\end{array}$ & CIMMYT \\
\hline G18 & $\begin{array}{l}\text { ALTAR 84/BINTEPE 85/3/ALTAR 84/STINT// SILVER_45/4/LHNKE/RASCON//CONA-DCD } \\
\text { SS99B01265T-0TOPY-0M-0Y-12Y-0M-0Y-1M-0Y }\end{array}$ & CIMMYT \\
\hline G19 & Saimareh & Iran \\
\hline G20 & Dehdasht & Iran \\
\hline
\end{tabular}

Table 2. Agro-climatic properties of the location tested in Iran

\begin{tabular}{|c|c|c|c|c|c|}
\hline Location & $\begin{array}{c}\text { Longitude } \\
\text { Latitude }\end{array}$ & $\begin{array}{l}\text { Altitude } \\
\text { (m) }\end{array}$ & Soil Texture & Soil Type & $\begin{array}{c}\text { Rainfall } \\
\text { (mm) }\end{array}$ \\
\hline Gachsaran & $\begin{array}{l}50^{\circ} 50^{\prime} \mathrm{E} \\
30^{\circ} 20^{\prime} \mathrm{N}\end{array}$ & 710 & Silty Clay Loam & Regosols & 455 \\
\hline Gonbad & $\begin{array}{l}55^{\circ} 12^{\prime} \mathrm{E} \\
37^{\circ} 16^{\prime} \mathrm{N}\end{array}$ & 45 & Silty Clay Loam & Regosols & 367 \\
\hline Khorram Abad & $\begin{array}{l}48^{\circ} 12^{\prime} \mathrm{E} \\
33^{\circ} 29^{\prime} \mathrm{N}\end{array}$ & 1125 & Silt-Loam & Regosols & 433 \\
\hline Ilam & $\begin{array}{l}46^{\circ} 36^{\prime} \mathrm{E} \\
33^{\circ} 47^{\prime} \mathrm{N}\end{array}$ & 975 & Clay-Loam & Regosols & 502 \\
\hline Moghan & $\begin{array}{l}47^{\circ} 88^{\prime} \mathrm{E} \\
39^{\circ} 39^{\prime} \mathrm{N}\end{array}$ & 100 & Sandy-Loam & Cambisols & 271 \\
\hline
\end{tabular}


Table 3. Equations of AMMI stability parameters used in this study

\begin{tabular}{|c|c|c|}
\hline Parameters & Equation & Author (s) \\
\hline EV & & Zobel (1994) \\
\hline AMGE & $\sum_{g=1} \lambda_{n} \gamma_{i n} \delta_{j n}$ & Sneller (1997) \\
\hline SIPC & $l_{n}^{0.5} \gamma_{\text {in }}$ & Sneller (1997) \\
\hline $\mathrm{D}$ & $\sqrt{\sum_{n=1}\left(\lambda_{n} \gamma_{i n}\right)^{2}}$ & Annicchiarico (1997) \\
\hline ASV & $\sqrt{\frac{S S I P C}{S S I P C} 2}(I P C 1)^{2}+(I P C 2)^{2}$ & Purchase (1997) \\
\hline MASV & $\sum_{K=1}^{N-1} \frac{\operatorname{SSIPC} n}{\operatorname{SSIPC}(n+1)}(\operatorname{IPC} n)^{2}+(\operatorname{IPC} n+1)^{2}$ & (Zali et al., 2012) \\
\hline
\end{tabular}

$\mathrm{EV}=$ Eigenvector, AMGE $=$ Sum across environments of GEI, SIPC $=$ Sum of the value of the IPC Scores, D = Parameter of Annicchiarico (1997), ASV = AMMI stability value, MASV = Modified AMMI Stability value (Zali et al., 2012).

\section{RESULTS AND DISCUSSION}

The combined analysis of variance was conducted to determine the effects of environment (location $\times$ year combination), genotype, and their interactions on grain yield of durum wheat genotypes (Table 4). The main effects of environment (E) and genotypes (G) were highly significant $(\mathrm{P}<0.01)$. The $\mathrm{GE}$ interaction was highly significant at $1 \%$ probability level $(\mathrm{P}<0.01)$. Environments had the largest effect, explaining $94.2 \%$ of total variability, while genotypes and GE interaction explained only 4.8 and $0.9 \%$ of total sum of squares, respectively (Table 4). The high significance of GE interactions for seed yield of durum wheat genotypes and its large magnitude of genotype main effect (larger than five times) are indicating that the studied genotypes exhibited complex GE interaction. Seed yield is a quantitative trait; its expression is the result of genotype, environmental factors and GE interaction. Cooper et al. (1995) mentioned that the large magnitude of GE interaction causes more dissimilarity in the genetic systems that are controlling the physiological processes that are conferring yield stability in different environments. The relative contributions of GE interaction effects for seed yield found in this study are similar to those found in other studies in rain-fed environments (Bertero et al., 2004; Sabaghnia et al., 2006; Karimizadeh and Mohammadi, 2010; Karimizadeh et al., 2012a; Sabaghnia et al., 2013). Therefore, GE interaction makes it difficult to select the best performing and most stable genotypes (Yau, 1995).

Table 4. Combined analysis of variance of durum wheat performance trial yield data

\begin{tabular}{|c|c|c|c|c|c|c|c|}
\hline Source & df & SS & MS & Propotion & Noise & Model & RMSPD $^{\mathbf{a}}$ \\
\hline Genotypes & 19 & 21661149 & $1140060 * *$ & $0.009^{\mathrm{c}}$ & $0.089^{\mathrm{e}}$ & - & - \\
\hline Environments & 19 & 2346434521 & $123496554 * *$ & $0.942^{c}$ & $0.001^{\mathrm{e}}$ & - & - \\
\hline Gen $\times$ Env & 361 & 123280605 & $341498 * *$ & $0.048^{c}$ & $0.297^{\mathrm{e}}$ & AMMIO & 462.31 \\
\hline IPCA 1 & 37 & 44742284 & $1209251 * *$ & $0.363^{\mathrm{d}}$ & - & AMMI1 & 452.65 \\
\hline IPCA 2 & 35 & 36143912 & $1032683 * *$ & $0.293^{\mathrm{d}}$ & - & AMMI2 & $439.15^{b}$ \\
\hline IPCA 3 & 33 & 9130861 & $276693 * *$ & $0.074^{\mathrm{d}}$ & - & AMMI3 & 451.11 \\
\hline IPCA 4 & 31 & 8559177 & $276102 * *$ & $0.069^{\mathrm{d}}$ & - & AMMI4 & 456.29 \\
\hline IPCA 5 & 29 & 5673139 & $195625 * *$ & $0.046^{\mathrm{d}}$ & - & AMMI5 & 461.58 \\
\hline Residuals & 196 & 19031232 & 97098 & - & $0.154^{\mathrm{f}}$ & AMMIF & 475.48 \\
\hline Error & 1140 & 115619600 & 101421 & - & - & - & - \\
\hline Total & 1599 & 2694270223 & 1684972 & - & - & - & - \\
\hline
\end{tabular}


Results indicated that only five IPCAs were significant at the 0.01 probability level. Similar to the results of AMMI model which is used in multi-environmental trials of durum wheat (Sabaghnia et al. 2012a; Sabaghnia et al. 2012b; Karimizadeh et al., 2012a; Sabaghnia et al. 2013; Mohammadi et al., 2015) or other crops like soybean (Zobel et al. 1988), lentil (Sabaghnia et al. 2008; Karimizadeh and Mohammadi, 2010), some of cereals (Annicchiarico, 1997) and chickpea (Dehghani et al., 2010, Zali et al., 2012), the AMMI model used in the this investigation showed relatively moderate complex GE interaction which required as many as three IPCAs. According to the root mean square prediction differences (RMSPD) in units of Yield $\left(\mathrm{kg} \mathrm{ha}^{-1}\right)$ are based on 1000 runs having 400000 validations with actual TRT data and zero validations with imputed data, so AMMI2 with 439.15 value is the best model for interpreting GE interaction and yield stability in this dataset (Table 4). From Table 3, it implies that the GE interaction is comprised of $29.7 \%$ noise and $70.03 \%$ signal. It is known that GE signal increases the number of useful megaenvironments whereas GE noise decreases the number of useful mega-environments (Annicchiarico, 1997). In the AMMI model, GE interaction effect of each genotype is further partitioned into effects due to individual environments. About $35 \%$ of the sum of squares of GEI would be loosed if we only judged based on crossvalidation procedure. In other words, this proportion of GEI was not playing any role in interpreting GEI. Cornelius (1993) expressed that one of the plant breeder's objectives is to obtain from the entire data set the best estimates of the true performance levels of the cultivars in the environments where they were evaluated, not to predict a subset from another subset. Since the crossvalidation might retain fewer terms than the optimum for the breeder's objective, selection of optimal model based on cross-validation seems to be more conservative than the other F-tests (Akbarpour et al., 2014). Annicchiarico (1997) and Cornelius (1993) also stated that selecting AMMI model by cross-validation tend to be conservative and this issue refers to deletion of one or half replications of full data set for calculating the modeling data. To overcome on this problem and to use the full data set for modeling data Moreno-Gonzalez et al. (2003) declared the theory of partitioning eigenvalue method (Akbarpour et al., 2014). The PCA based on GE interaction showed that the cumulative contributions of the first five components accounted for over $84 \%$ of the total variation in seed yield (Table 5). Similar to the results obtained using AMMI models for the analysis of multi-environment trials of durum wheat (Sabaghnia et al., 2013) and different crops such as soybean, citrus and lentil (Zobel et al., 1988; Iwata et al., 2002; Sabaghnia et al., 2008), the AMMI model used in the present investigation exhibited complex interaction requiring as many as five IPCAs.
Table 5. Eigenvalues and contributions of the first five principal components

\begin{tabular}{lccc} 
Components & Eigenvalue & Proportion & Cumulative \\
\hline IPCA 1 & $1.12 \times 10^{+7}$ & 36.29 & 36.29 \\
IPCA 2 & $9.04 \times 10^{+6}$ & 29.32 & 65.61 \\
IPCA 3 & $2.28 \times 10^{+6}$ & 7.41 & 73.02 \\
IPCA 4 & $2.14 \times 10^{+6}$ & 6.94 & 79.96 \\
IPCA 5 & $1.42 \times 10^{+6}$ & 4.60 & 84.56 \\
Total & $3.08 \times 10^{+7}$ & - & - \\
Variance & & & - \\
\hline
\end{tabular}

However, five types of AMMI parameters were calculated as EV1, AMGE1, SIPC1 and D1 parameters (using only one IPCA), EV2, AMGE2, SIPC2 and D2 parameters (based on RMSPD results and using IPCA1 and IPCA2), EV3, AMGE3, SIPC3 and D3 parameters (using the first three IPCAs. Considering explained variation due to each IPCAs, type 1-based parameters benefits $36.29 \%$, RMSPD-based parameters benefits $65.61 \%$, type 3-based parameters benefits $73.02 \%$, type 4based parameters benefits $79.96 \%$, and type 4-based parameters benefits $84.56 \%$ of GE interaction variations (Table 4). It is clear that calculating AMMI stability parameters based on the larger numbers of IPCAs results in the most usage of GE interaction variations.

According to minimum values EV1 and D1 parameters, and minimum absolute values of SIPC1 parameters, genotypes G2, G5, G7 and G8 were the most stable genotypes and AMGE1 results showed that G2, G5, G7, G17 and G18 were the most stable genotypes (Tables 6 and 7). These stable genotypes indicated low mean yield across test environments and so could not be considered as the most favorable genotypes. It can be stated that, these genotypes had static concept of stability which equal to homeostasis phenomenon of quantitative genetics. Anyhow, most plant breeders have used the stability similar to the above targets and to determine a genotype which shows a relatively constant yield in various environmental (Becker, 1981). Also, stable genotypes with static concept do not necessarily respond to improved growing conditions with increased yield (Becker and Leon, 1988).

Genotypes G8, G11, G14 and G19 were the most stable genotypes based on EV2 and D2 parameters, genotypes G4, G11, G16 and G17 were the most stable genotypes based on SIPC2 parameter, and genotypes G5, G9, G14and G18 were the most stable genotypes based on AMGE2 parameter (Tables 6 and 7). Although, most of these genotypes had not the high mean yield performance, but some genotypes (G10, G11, G12 following to G8) showed relatively high mean yield. In recent decades, most plant breeders would prefer an agronomic concept of stability instead of static concept of stability (Becker and Leon 1988). In agronomic or dynamic concept of stability 
it is not required that the genotypic response to environmental conditions should be equal for all genotypes. It seems that using first two IPCAs in stability analysis could benefits dynamic concept of stability in identification of the most stable genotypes and high mean yield.

According to minimum values EV3, SIPC3 and D3 parameters, genotypes G4, G5, G10, G11, G14, G17 and G18 were the most stable genotypes while based on minimum absolute values of AMGE3 parameter, genotypes G6, G8, G12 and G18 were the most stable genotypes and genotypes G3 and G20 were the unstablest genotypes (Tables 6 and 7). In this research we calculated standard deviation of each AMMI parameters and result showed that EV standard deviation for genotypes G4, G17, G5, G10, G8, G14, G16 and the D standard deviation for genotypes G4, G5, G8, G14 and G18 also were lowest values. The SIPC standard deviation for genotypes G4, G6, G10, G11, G14, G17, G19 and the AMGE standard deviation for genotypes G5, G6, G7, G14, G17 and G19 also were lowest values (Tables 6 and 7). In this research Only genotypes G10 and G12 had high mean yield and genotypes G8, G4, G11 and G17 had moderate mean yield while the other most stable genotypes had relatively low mean yield.

According to ASV parameter, genotypes G11, G14, G19 and G17 were the most stable genotypes while genotypes G1, G13 and G9 were the most unstable genotypes (Table 6). Considering first two IPCAs in ASV parameter, $39.46 \%$ of GE interaction is used in GE interaction exploration. The two IPCAs have different values and meanings and the ASV parameter using the Pythagoras theorem and to get estimated values between IPCA1 and IPCA2 scores to produce a balanced parameter between the two IPCA scores (Purchase, 1997). Also, ASV parameter of this investigation used advantages of cross validation due to computation from first two IPCAs. The results of ASV parameter have many similarities with the other AMMI stability parameters which calculated from the first two IPCAs scores. According to MASV parameter, genotypes G11, G14, and G19 were the most stable genotypes while genotypes G9, and G15 were the most unstable genotypes (Table 7). Considering first five IPCAs in MASV parameter, $84.56 \%$ of GE interaction is used in GE interaction exploration. The results of MASV parameter have many similarities with the other AMMI stability parameters which calculated from the first two IPCAs scores. Finally according to the most of type 1 of AMMI parameters (EV1, AMGE1, SIPC1 and D1), genotypes G8, G17 and G11; based on the type 2 of AMMI parameters (EV2, AMGE2, SIPC2, D1 and ASV), genotypes G4, G5, G10, G11 and G17; due to type 3 of AMMI parameters (EV3, AMGE3, SIPC3 and D3 and MASV), genotypes G8, G10 and G12 were detected as the most stable genotypes. Considering all of the AMMI stability parameters, genotypes G8, G10, G11, G12 and G17 following to genotypes G7 and G9 were the most stable genotypes. Among these stable genotypes, only genotypes G10 and G9 had the high mean yield performance (3470 and $3404 \mathrm{~kg} \mathrm{ha}^{-1}$ ) whiles the yield performance of $\mathrm{G} 7, \mathrm{G} 8, \mathrm{G} 11$ and $\mathrm{G} 2$ had moderate mean grain yield.

Table 6. The EV and D parameters of AMMI model for durum wheat yields of 20 genotypes tested in 20 environments

\begin{tabular}{lcccccccccc}
\hline Genotype & MGY & EV $_{\mathbf{1}}$ & $\mathbf{E V}_{\mathbf{2}}$ & $\mathbf{E V}_{\mathbf{3}}$ & STDEV & $\mathbf{D}_{\mathbf{1}}$ & $\mathbf{D}_{\mathbf{2}}$ & $\mathbf{D}_{\mathbf{3}}$ & STD & ASV \\
\hline G1 & 3264 & 0.193 & 0.101 & 0.081 & 0.060 & 1470 & 1752 & 3522 & 1112 & 28.74 \\
G2 & 3098 & 0.000 & 0.052 & 0.044 & 0.028 & 54 & 1017 & 1334 & 667 & 17.60 \\
G3 & 3074 & 0.069 & 0.035 & 0.060 & 0.018 & 881 & 986 & 2364 & 827 & 17.05 \\
G4 & 3231 & 0.013 & 0.022 & 0.016 & 0.005 & 379 & 906 & 1380 & 501 & 12.07 \\
G5 & 3203 & 0.002 & 0.027 & 0.019 & 0.013 & 156 & 844 & 1072 & 477 & 12.90 \\
G6 & 3066 & 0.041 & 0.024 & 0.061 & 0.018 & 677 & 938 & 2170 & 797 & 13.87 \\
G7 & 3153 & 0.002 & 0.040 & 0.064 & 0.031 & 142 & 987 & 1633 & 747 & 15.65 \\
G8 & 3239 & 0.005 & 0.015 & 0.014 & 0.006 & 228 & 707 & 1090 & 432 & 9.77 \\
G9 & 3404 & 0.043 & 0.121 & 0.089 & 0.039 & 691 & 2030 & 2961 & 1141 & 27.81 \\
G10 & 3470 & 0.028 & 0.039 & 0.026 & 0.007 & 560 & 1231 & 1844 & 642 & 16.30 \\
G11 & 3207 & 0.010 & 0.006 & 0.007 & 0.002 & 338 & 438 & 921 & 312 & 6.76 \\
G12 & 3343 & 0.118 & 0.089 & 0.080 & 0.020 & 1150 & 1880 & 3405 & 1151 & 25.82 \\
G13 & 2995 & 0.175 & 0.107 & 0.073 & 0.052 & 1400 & 1989 & 3501 & 1083 & 29.00 \\
G14 & 3073 & 0.021 & 0.011 & 0.007 & 0.007 & 482 & 554 & 1037 & 301 & 9.37 \\
G15 & 3252 & 0.047 & 0.118 & 0.082 & 0.035 & 728 & 2035 & 2918 & 1102 & 27.65 \\
G16 & 3143 & 0.035 & 0.044 & 0.048 & 0.007 & 626 & 1323 & 2308 & 845 & 17.52 \\
G17 & 3200 & 0.014 & 0.025 & 0.018 & 0.005 & 402 & 971 & 1463 & 531 & 12.95 \\
G18 & 3222 & 0.045 & 0.026 & 0.020 & 0.013 & 712 & 964 & 1806 & 573 & 14.45 \\
G19 & 3089 & 0.026 & 0.013 & 0.045 & 0.016 & 539 & 568 & 1605 & 607 & 10.39 \\
G20 & 3120 & 0.111 & 0.085 & 0.147 & 0.031 & 1116 & 1845 & 3747 & 1358 & 25.26 \\
\hline
\end{tabular}


Table 7. The SIPC and AMGE stability parameters of AMMI model for durum wheat yields of 20 genotypes tested in 20 environments

\begin{tabular}{lcccccccccc}
\hline Genotype & MGY & SIPC $_{1}$ & SIPC $_{2}$ & SIPC $_{3}$ & STD $_{\text {IIPC }}$ & AMGE $_{1}$ & AMGE $_{2}$ & AMGE $_{3}$ & STD $_{\text {AMGE }}$ & MASV \\
\hline G1 & 3264 & 25.5 & 20.3 & 53.6 & 17.9 & 537 & 481 & 913 & 235 & 48.40 \\
G2 & 3098 & -0.9 & -18.6 & -12.7 & 9.0 & 0.02 & 81 & 134 & 68 & 57.90 \\
G3 & 3074 & -15.3 & -13.3 & -41.5 & 15.7 & -753 & -773 & -1588 & 476 & 41.54 \\
G4 & 3231 & 6.6 & -3.1 & 1.0 & 4.8 & -53 & 36 & -38 & 48 & 35.13 \\
G5 & 3203 & -2.7 & -15.3 & -16.1 & 7.5 & 9 & 23 & 48 & 20 & 43.35 \\
G6 & 3066 & 11.7 & 7.0 & 4.4 & 3.7 & -57 & -61 & -13 & 27 & 43.59 \\
G7 & 3153 & -2.5 & -17.9 & -33.4 & 15.5 & 13 & 106 & 124 & 59 & 55.13 \\
G8 & 3239 & -4.0 & -12.7 & -20.7 & 8.4 & 24 & 62 & 20 & 23 & 42.88 \\
G9 & 3404 & 12.0 & 36.5 & 42.3 & 16.1 & 36 & 3 & 120 & 60 & 81.18 \\
G10 & 3470 & 9.7 & 22.0 & 10.3 & 6.9 & -59 & -103 & -161 & 51 & 42.30 \\
G11 & 3207 & -5.9 & -4.1 & -13.7 & 5.1 & 34 & 33 & 75 & 24 & 21.06 \\
G12 & 3343 & 19.9 & 6.6 & 36.2 & 14.8 & -60 & 31 & 10 & 48 & 55.58 \\
G13 & 2995 & -24.3 & -35.1 & -56.5 & 16.4 & 167 & 176 & 322 & 87 & 52.84 \\
G14 & 3073 & -8.4 & -7.1 & -15.4 & 4.5 & 31 & 25 & 55 & 16 & 20.28 \\
G15 & 3252 & 12.6 & 36.5 & 53.2 & 20.4 & -92 & -109 & -246 & 84 & 80.43 \\
G16 & 3143 & -10.9 & 1.9 & -18.2 & 10.2 & 79 & 86 & 286 & 118 & 47.18 \\
G17 & 3200 & -7.0 & 3.4 & -5.8 & 5.7 & 12 & 38 & 26 & 13 & 36.59 \\
G18 & 3222 & 12.3 & 7.7 & 23.4 & 8.1 & -12 & 17 & 25 & 20 & 31.09 \\
G19 & 3089 & -9.4 & -8.8 & -5.4 & 2.2 & 43 & 41 & 42 & 1 \\
G20 & 3120 & -19.4 & -6.0 & -5.1 & 8.0 & -23 & 638 & 773 & 426 & 63.96 \\
\hline
\end{tabular}

First four AMMI's in this research ranked genotypes based on yield stability (Table 8). In this research, G10 genotype was chosen as the most stable genotype with 16 being chosen between first four genotypes by AMM1 till AMMI4, followed by G12 with 12 being between 4 superior genotypes, was chosen as the second rank. Finally, although G8 won first place in 4 locations at the second year, however by 6 times being between four superior genotypes, was selected as third stable genotypes. The best recommended genotypes according to the present study are G10 with $3470 \mathrm{~kg} \mathrm{ha}^{-1}$ grain yield for Gachsaran and Khorramabad, G12 with $3343 \mathrm{~kg} \mathrm{ha}^{-1}$ grain yield for Ilam and G10 and G12 for Moghan and Gonbad regions which had high mean yield and were most stable for related mega-environments.

Table 8. First four AMMI selections of genotypes per each environment

\begin{tabular}{lccccc}
\hline Environment & Mean Yield & AMMI1 & AMMI2 & AMMI3 & AMMI4 \\
\hline E1 & 3398 & G10 & G1 & G9 & G12 \\
E2 & 1952 & G10 & G12 & G9 & G3 \\
E3 & 5313 & G1 & G12 & G18 & G6 \\
E4 & 4801 & G8 & G7 & G13 & G10 \\
E5 & 4203 & G10 & G9 & G7 & G8 \\
E6 & 2260 & G10 & G20 & G15 & G12 \\
E7 & 1307 & G8 & G10 & G12 & G4 \\
E8 & 3185 & G8 & G7 & G9 & G10 \\
E9 & 3559 & G8 & G12 & G18 & G10 \\
E10 & 3357 & G8 & G10 & G12 & G7 \\
E11 & 4935 & G5 & G15 & G6 & G14 \\
E12 & 3717 & G11 & G4 & G9 & G2 \\
E13 & 3508 & G20 & G10 & G5 & G12 \\
E14 & 1161 & G5 & G12 & G10 & G1 \\
E15 & 2414 & G20 & G11 & G9 & G17 \\
E16 & 2117 & G20 & G10 & G19 & G12 \\
E17 & 4697 & G9 & G10 & G3 & G11 \\
E18 & 1786 & G10 & G3 & G5 & G12 \\
E19 & 2222 & G5 & G12 & G10 & G19 \\
E20 & 3951 & G9 & G15 & G10 & G16 \\
\hline
\end{tabular}




\section{CONCLUSIONS}

Successful genotypes of durum wheat need to be adapted to a broad range of environmental conditions in order to ensure their yield stability. Hence, the information on GE interaction and stability is of paramount importance for durum wheat breeders and farmers. It is clear that the AMMI model is excellent tools for multi-environment trials analysis. Compared with conventional methods of the multi-environment trials dataset analysis, the AMMI model approach has some advantages (Gauch, 2006; Gauch et al., 2008). Selection of genotypes for stability is needed in most dryland environments, where the environment is variable and unpredictable. Therefore, genotype evaluation under variable environmental conditions and simultaneous selection for yield and stability is the most valuable selection index that can be used in any plant breeding program. Such an outcome could be regularly employed in the future to delineate predictive, more rigorous recommendation strategies as well as to help define stability concepts for recommendations for durum wheat and other crops in other areas of the world.

The stability statistics that has been employed in the present study quantified yield stability of genotypes. Despite the fact that the different stability procedures are indicative, the AMMI model provides useful information for reaching definitive conclusions. Therefore, the identifying mega-environments and related wining genotypes are indispensable, as farmers would prefer to use a high-yielding genotype that performs consistently from test environment to test environment. Thus, the best recommended genotypes according to the present study are G10 with $3470 \mathrm{~kg} \mathrm{ha}^{-1}$ grain yield for locations Gachsaran and Khorram ababd, G12 with $3343 \mathrm{~kg} \mathrm{ha}^{-1}$ ) for Ilam location and both G10 and G12 for locations Gonbad and Moghan which had high mean yield and were the most stable for related mega- environments.

\section{ACKNOWLEDGMENTS}

The authors thank the Iranian Dry Agricultural Research Organization for making available the plant materials, experimental locations and technical assistance.

\section{LITERATURE CITED}

Adugna, W. and M.T. Labuschagne. 2002. Genotype $\times$ environment interactions and phenotypic stability analyses of linseed in Ethiopia. Plant Breed. 121:66-71.

Akbarpour, O., H. Dehghani, B. Sorkhi and G. Guach. 2014. Evaluation of Genotype $\times$ Environment Interaction in Barley (Hordeum Vulgare L.) Based on AMMI model Using Developed SAS Program. J. Agric. Sci. Tech. 16: 919-930.

Akcura, M., Y. Kaya and S. Taner. 2009. Evaluation of durum wheat genotypes using parametric and nonparametric stability statistics. Turk. J. Field Crop. 14(2): 111-122.

Annicchiarico, P. 1997. Joint regression vs AMMI analysis of genotype $\times$ environment interactions for cereals in Italy. Euphytica 94:53-62.

Annicchiarico, P. 2002. Genotype $\times$ environment interaction: challenges and opportunities for plant breeding and cultivar recommendations, Food and Agriculture Organization of the United Nations.
Becker, H.C. 1981. Correlations among some statistical measures of phenotypic stability. Euphytica 30: 835-840.

Becker, H.C. and J. Leon. 1988. Stability analysis in plant breeding. Plant Breed. 101:1-23.

Bertero H.D., A.J.G. dela Vega Correa, S.E. Jacobsen and A. Mujic. 2004. Genotype and genotype-by-environment interaction effects for grain yield seed yield and grain size of quinoa (Chenopodium quinoa Wild.) as revealed by pattern analysis of international multi-environment trials. Field Crops Res. 89: 299-318.

Burgueño, J., J. Crossa and M. Vargas. 2000. SAS programs for graphing GE and GGE biplots. Biometrics and Statistics Unit, Centro Internacional de Mejoramiento de Maíz y Trigo (CIMMYT), México.

Cooper, M., D.R. Woodruff, R.L. Eisemann, P.S. Brennan and I.H. DeLacy. 1995. A selection strategy to accommodate genotype-by-environment interaction for grain yield, seed yield of wheat: managed-environments for selection among genotypes. Theor. Appl. Genet. 90: 492-502.

Cornelius, P.L. 1993. Statistical tests and retention of terms in the additive main effects and multiplicative interaction model for cultivar trials. Crop Sci. 33: 1186-1193.

Cornelius, P.L., J. Crossa and M. Seyedsadr. 1996. Statistical tests and estimators of multiplicative models for cultivar trials. In: Kang, M.S. and Gauch, H.G., Jr (eds) Genotypeby-Environment Interaction. CRC Press, Boca Raton, Florida, pp. 199-234.

Dehghani, H., S.H. Sabaghpour and A. Ebadi. 2010. Study of genotype $\times$ environment interaction for chickpea yield in Iran. Agron. J. 102: 1-8.

Ebdon, J.S. and H.G. Gauch. 2002. AMMI analysis of national turfgrass

performance trials. II. cultivar recommendations. Crop Sci. 42: 497-506 11 .

Eberhart, S.A. and W.A. Russell. 1966. Stability parameters for comparing varieties. Crop Sci. 6: 36-40.

Finlay, K.W. and G.N. Wilkinson. 1963. The analysis of adaptation in a plant-breeding programme. Aus. J. Agric. Res. 14: 742-754.

Fisher, R.A. and W.A. MacKenzie. 1923. Studies in variation II. The manorial response in different potato varieties. J. Agric. Sci. 13: 311-320.

Gabriel, K.R. 1978. Least squares approximation of matrices by additive and multiplicative models. J. Royal Stat. Soc. 40: 186-196.

Gauch, H.G. 1988. Model selection and validation for yield trials with interaction. Biometrics 44:705-715.

Gauch, H.G. and R.W. Zobel. 1996. AMMI analysis of yield trials. In Kang, M.S., Gauch, H.G. (ed.) Genotype by environment interaction. CRC Press, Boca Raton, FL.

Gauch, H.G. and R.W. Zobel. 1997. Identifying megaenvironments and targeting genotypes. Crop Sci. 37: 311326.

Gauch, H.G. 2006. Statistical analysis of yield trials by AMMI and GGE. Crop Sci. 46:1488-1500.

Gauch, H.G., H.P. Piepho and P. Annicchiarico. 2008. Statistical analysis of yield trials by AMMI and GGE. Further considerations. Crop Sci. 48:866-889.

Gollob, H.F. 1968. A statistical model which combines features of factor analysis and analysis of variance techniques. Psychometrika 33: 73-115.

Ilker, E., H. Geren, R. Unsal, I. Sevim, F. Aykut Tonk, and M. Tosun. 2011. AMMI-biplot analysis of yield performances of bread wheat cultivars grown at different locations. Turk $\mathrm{J}$ Field Crops. 16(1): 64-68.

Iwata H., H. Nesumi, S. Ninomiya, Y. Takano, and Y. Ukai. 2002. The evaluation of genotype $\times$ environment interactions 
of citrus leaf morphology using image analysis and elliptic fourier descriptors. Breeding Sci. 52: 243-251.

Johnson, D.E. and F.A. Graybill. 1972. An analysis of a two-way model with interaction and no replication. J. Am. Stat. Assoc. 67: 862-868.

Kang, M.S., 1998. Using genotype by environment interaction for crop cultivar development. Adv. Agron. 35: 199-240.

Karimizadeh, R. and M. Mohammadi, M. 2010. AMMI adjustment for rainfed lentil yield trials in Iran. Bul. J. Agric. Sci. 16: 66-73.

Karimizadeh, R., M. Mohammadi, M. Armion, M.K. Shefazadeh and, H. Chalajour. 2012a. Determining heritability, reliability and stability of grain yield and yield-related components in durum wheat (Triticum durum L.). Bul. J. Agric. Sci. 18(4): 595-607.

Karimizadeh, R., M. Mohammadi, M.K. Shefazadeh, A.A. Mahmoodi, B. Rostami, and F. Karimpour. 2012b. Relationship among and repeatability of ten stability indices for grain yield of food lentil genotypes in Iran. Turk. J. Field Crops. 17(1): 51-61.

Mandel, J. 1961. Non-additivity in two-way analysis of variance. J. Am. Stat. Assoc. 56: 878-888.

Mandel, J. 1971. New analysis of variance model for nonadditive data. Technometrics 13:1-18.

Mladenov, V., B. Banjac, and M. Milosevic. 2012. Evaluation of Yield and Seed Requirements Stability of Bread Wheat (Triticum aestivum L.) Via AMMI Model. Turk. J. Field Crops. 17(2): 203-207.

Mohammadi, M., P. Sharifi, R. Karimizadeh, J.A. Jafarby, H. Khanzadeh, T. Hosseinpour, M.M. Poursiabidi, M. Roustaii, M. Hassanpour Hosni, and P. Mohammadi. 2015. Stability of grain yield of durum wheat genotypes by AMMI model. Agric. For. 61(3): 181-193.

Mohammadi, M., R. Karimizadeh, N. Sabaghnia, and M.K. Shefazadeh. 2012. Genotype $\times$ Environment Interaction and Yield Stability Analysis of New Improved Bread Wheat Genotypes. Turk. J. Field Crop. 17(1): 67-73.

Moreno-Gonzalez, J., J. Crossa and P.L. Cornelius. 2003. Additive Main Effects and Multiplicative Interaction Model. I. Theory on Variance Components for Predicting Cell Means. Crop Sci. 43: 1967-1975.

Nachit, M.M. 1992. Use of AMMI and linear regression models to analyze genotype environment interaction in durum wheat. Theor. Appl. Genet. 83: 597-601.

Payne, R.W., D.A. Murray, S.A. Harding, D.B. Baird, and D.M. Soutar. 2009. GenStat for Windows (12th Edition) Introduction. VSN International, Hemel Hempstead.

Purchase, J. L. 1997. Parametric analysis to describe $\mathrm{G} \times \mathrm{E}$ interaction and yield stability in winter wheat. Ph.D. thesis. Dep. of Agronomy, Faculty of Agriculture, Univ. of the Orange Free State, Bloemfontein, South Africa.

Sabaghnia, N., H. Dehghani and S.H. Sabaghpour. 2006. Nonparametric methods for interpreting genotype $\times$ environment interaction of lentil genotypes. Crop Sci 46: 1100-1106.

Sabaghnia, N., S.H. Sabaghpour and H. Dehghani, 2008. The use of an AMMI model and its parameters to analyze yield stability in multi-environment trials. J. Agric. Sci. 146:571581.

Sabaghnia, N., M. Mohammadi and R. Karimizadeh, 2012a. The evaluation of genotype $\times$ environment interactions of durum wheat's yield using of the AMMI model. Agric. For. 55(9): 5-21.

Sabaghnia, N., R. Karimizadeh and M. Mohammadi. 2012b. Model selection in additive main effect and multiplicative interaction model in durum wheat. Genetika 44(2): 325-339.

Sabaghnia, N., M. Mohammadi and R. Karimizadeh. 2013. Parameters of AMMI model for yield stability analysis in durum wheat. Agric. Con. Sci. 78(2): 119-124.

Sneller, C.H., L. Kilgore-Norquest and D. Dombek. 1997. Repeatability of yield stability statistics in soybean. Crop Sci. 37: 383-390.

Solomon, K.F., H.A. Smit, E. Malan and W.J. Du Toit. 2008. Parametric model based assessment of genotype $x$ environment interactions for grain yield in durum wheat under irrigation. Int. J. Plant Pro. 2(1): 23-26.

Tukey, J.W. 1949. One degree of freedom for non-additivity. Biometrics 5: 232-242.

Williams, E.J. 1952. The interpretation of interactions in factorial experiments. Biometrika 39:65-81.

Wold, S. 1978. Cross-validatory Estimation of the Number of Components in Factor and Principal Component Models. Technometrics 20: 397-405.

Yan, W., L.A., Hunt, Q. Sheng, and Z. Szlavnics. 2000. Cultivar evaluation and mega-environment investigations based on the GGE biplot. Crop Sci. 40: 597-605.

Yates, F. and W.G. Cochran. 1938. The analysis of groups of experiments. J. Agric. Sci. 28: 556-580.

Yau, S.K. 1995. Regression and AMMI analyses of genotype $\times$ environment interactions: An empirical comparison. Agron. J. 87: $121-126$.

Yue, G., K.L. Roozeboom, W.T. Schapaughjr and G.H. Liang. 1997. Evaluation of soybean cultivars using parametric and nonparametric stability estimates. Plant Breed. 116:271-275.

Zali, H., E. Farshadfar, S.H. Sabaghpour and R. Karimizadeh. 2012. Evaluation of genotype $\times$ environment interaction in chickpea using measures of stability from AMMI model. Annal. Bio. Res. 3(7): 3126-3136.

Zobel, R.W. 1994. Stress resistance and root systems. p. 80-99. In Proc. Of the Workshop on Adaptation of Plants to Soil Stress. 1-4 Aug. 1993. INTSORMIL Publ. 94-2. Inst. of Agriculture and Natural Resources, Univ. of Nebraska, Lincoln.

Zobel, R.W., M.J. Wright and H.G. Gauch. 1988. Statistical analysis of a yield trial. Agron. J. 80:388-393. 